\title{
JUSTICIA CULTURAL Y POLÍTICAS PÚBLICAS: DE LAS ACCIONES AFIRMATIVAS A LAS POLÍTICAS INTERCULTURALES (UNA PROPUESTA NORMATIVA PARA EL CASO DE LOS GRUPOS ÉTNICOS)*
}

\section{CULTURAL JUSTICE AND PUBLIC POLICY: THE AFFIRMATIVE ACTION TO CROSS- CULTURAL POLICY (A NORMATIVE PROPOSAL FOR THE CASE OF ETHNIC GROUPS)}

\author{
Edwin Cruz Rodríguez**
}

Fecha de recepción: 22 de enero del 2013 Fecha de aprobación: 2 de mayo del 2013

\section{Para citar este artículo / To cite this article}

Cruz Rodríguez, Edwin, Justicia cultural y políticas públicas: de las acciones afirmativas a las políticas interculturales (una propuesta normativa para el caso de los grupos étnicos) 127 Vniversitas, 91-125 (2013) doi:10.1144/Javeriana.VJ127.jcpp

Artículo de reflexión fruto de la investigación "Multiculturalismo e interculturalidad: los desafíos de la diversidad", que el autor desarrolló durante el primer semestre del 2011 como requisito para la actividad "Examen de calificación", en el marco del doctorado en Estudios Políticos y Relaciones Internacionales de la Universidad Nacional de Colombia.

** Politólogo, especialista en Análisis de Políticas Públicas de la Universidad Nacional de Colombia, magíster en Análisis de Problemas Políticos, Económicos e Internacionales Contemporáneos de la Universidad Externado de Colombia; candidato a Doctor en Estudios Políticos y Relaciones Internacionales e integrante del Grupo de Investigación en Teoría Política Contemporánea, Teopoco, de la Universidad Nacional de Colombia. Correo electrónico: ecruzr@unal.edu.co 


\section{RESUMEN}

Este artículo de reflexión fundamenta las diferencias entre las acciones afirmativas y las políticas interculturales. En primer lugar, plantea un marco hermenéutico que reconstruye el enfoque multicultural de Kymlicka y el interculturalismo latinoamericano. En segundo lugar, y con base en ese marco, establece las diferencias entre acciones afirmativas y políticas interculturales. El planteamiento central es que las acciones afirmativas son necesarias, pero no suficientes, para alcanzar los ideales del interculturalismo: el diálogo, el respeto, la convivencia y el aprendizaje mutuo entre culturas.

Palabras clave autor: Multiculturalismo, interculturalidad, grupos étnicos, acciones afirmativas, políticas interculturales.

Palabras clave descriptores: Multiculturalismo, grupos étnicos, política cultural, etnicidad, América Latina. 


\section{ABSTRACT}

This reflection paper bases the differences between affirmative action and intercultural policies. First, it presents an hermeneutical framework that reconstructs the multicultural approach of Kymlicka and Latin American interculturalism. Secondly, and based on that framework, it establishes the differences between affirmative action and intercultural policies. The central idea is that affirmative action is necessary, but not sufficient to achieve the ideal of interculturalism: dialogue, respect, coexistence and mutual learning between cultures.

Keywords author: Multiculturalism, interculturalism, ethnic groups, affirmative action, intercultural policies.

Keywords plus: Multiculturalism, ethnic groups, cultural policy, ethnicity, Latin America.

\section{SUMARIO}

INTRODUCCIÓN.- I. DERECHOS DIFERENCIADOS Y JUSTICIA CULTURAL: MULTICULTURALISMO E INTERCULTURALISMO.- A. La justicia cultural en el multiculturalismo de Kymlicka.- B. La crítica del multiculturalismo y el concepto de interculturalidad.- 1 . La crítica metodológica.- 2. La crítica de los fines.- 3. La crítica de los medios.- II. ACCIÓN ESTATAL Y JUSTICIA CULTURAL.- A. Las acciones afirmativas. - B. Hacia las políticas interculturales. - 1. Lógica mayorías/minorías versus lógica dominación/subalternidad.- 2. Más allá de las políticas correctivas.- 3. Convivencia versus coexistencia.- 4. Políticas participativas.- 5. Políticas de largo plazo o permanentes.- CONCLUSIONES. 


\section{INTRODUCCIÓN}

En el último tercio del siglo XX una de las principales preocupaciones de la filosofía jurídica, política y moral, fue la de alcanzar la justicia entre culturas. Tal inquietud se explica por la emergencia de grupos culturales, minorías nacionales o inmigrantes, que demandaron el reconocimiento de derechos y políticas diferenciadas.

Esta problemática se conoció como "multiculturalismo". En sentido descriptivo, el término designa la existencia de la diversidad cultural en un espacio ${ }^{1}$. Sin embargo, el influyente trabajo de Will Kymlicka ${ }^{2}$ revistió el concepto de un contenido normativo, al formular un enfoque para alcanzar la justicia entre culturas conciliando los derechos individuales con derechos específicos de grupo. De la mano de esta perspectiva, se desarrollaron reformas alrededor del mundo, reconociendo derechos diferenciados, y se afianzaron las acciones afirmativas como un mecanismo complementario para alcanzar la justicia entre culturas ${ }^{3}$.

El multiculturalismo, tanto en sentido descriptivo como en referencia al enfoque de Kymlicka, planteó arduas discusiones en América Latina, que contribuyeron al planteamiento de una perspectiva con fundamentos normativos diferentes: la interculturalidad. Este concepto fue apropiado por los movimientos indígenas, alrededor de los ochenta, como alternativa al multiculturalismo, que se articuló a las políticas de ajuste estructural, pero más tarde fue desarrollado en distintos campos ${ }^{4}$.

1 Multiculturalismo es un término problemático porque se refiere a fenómenos muy distintos —en su sentido más amplio al feminismo, el ecologismo, las minorías sexuales o de género, los inmigrantes y las poblaciones indígenas o minorías nacionales-, que aunque comparten la reivindicación de dimensiones colectivas marginadas por los supuestos teóricos del liberalismo clásico, requieren un trato analítico diferenciado. Ferrán Requejo, Pluralismo, democracia y federalismo. Una revisión de la ciudadanía democrática en estados plurinacionales, Revista Internacional de Filosofía Política, No. 7, 94 (1996). El problema radica en que muchos de esos fenómenos no pueden considerarse como "culturas" o grupos culturales, por lo que es preciso examinarlos en su particularidad. Francisco Colom, Las identidades culturales y la dinámica del reconocimiento, en: F. Cortés \& A. Monsalve, Coords., Multiculturalismo. Los derechos de las minorías culturales, Universidad de Antioquia, Murcia, 40-41. (1999).

2 Will Kymlicka, Ciudadanía multicultural, Paidós, Buenos Aires (1996).

3 Este trabajo se ocupa únicamente de las acciones afirmativas orientadas a grupos étnicos. Las acciones afirmativas no se especializan en los grupos étnicos, sino que tienen poblaciones objeto más amplias, pues están dirigidas a igualar la situación de discriminación a la que se ven sometidos distintos sujetos por su condición étnica, racial, sexual o de género, e incluso física.

4 El concepto de interculturalidad, al igual que el de multiculturalismo, presenta distintos 
Bajo influjo de este enfoque, en los últimos años se ha empezado a hablar de políticas interculturales ${ }^{5}$. La categoría de interculturalidad está íntimamente ligada al desarrollo de las políticas educativas para pueblos indígenas y afrodescendientes, la Educación Intercultural Bilingüe (EIB). Sin embargo, no siempre se tienen en cuenta las implicaciones del concepto de interculturalidad para la acción pública estatal. Por el contrario, con frecuencia se confunden las políticas interculturales con las acciones afirmativas, y no existe una aproximación sistemática a sus diferencias y similitudes.

Este artículo se ocupa de fundamentar esas diferencias. Sostiene que las acciones afirmativas son necesarias, pero insuficientes, para conseguir los ideales del interculturalismo, el diálogo, el respeto, la convivencia y el aprendizaje mutuo entre culturas en condiciones de igualdad, y que se requieren políticas interculturales que promuevan estos valores. Para desarrollar este argumento, en primer lugar, se plantea un marco hermenéutico que reconstruye la perspectiva multicultural de Kymlicka y, a partir de su crítica, el enfoque intercultural. Con base en este marco, en segundo lugar, se establecen las distinciones entre las acciones afirmativas y las políticas interculturales.

\section{DERECHOS DIFERENCIADOS Y JUSTICIA CULTURAL: MULTICULTURALISMO E INTERCULTURALISMO}

Kymlicka media en el debate entre liberales y comunitaristas, tomando partido por los primeros, pero apartándose de algunos de

usos y significados. Algunos autores establecen distinciones entre interculturalidad como un concepto descriptivo para designar la diversidad cultural e interculturalismo como un concepto normativo. Catherine Walsh, Interculturalidad, plurinacionalidad y decolonialidad: las insurgencias político-epistémicas de refundar el Estado, Tabula rasa, No. 9, 140 (2008). Otros distinguen una "interculturalidad crítica" y una "interculturalidad funcional". Fidel Tubino, No una sino muchas ciudadanias: una reflexión desde el Perú y América Latina, 6 Cuadernos Interculturales, No. 10, 175 (2008); Fidel Tubino, El nivel epistémico de los conflictos interculturales, 7 Revista electrónica construyendo nuestra interculturalidad, Nos. 6-7, 10-12 (2011). En este trabajo se usan los términos de interculturalidad e interculturalismo para designar el enfoque normativo alternativo al multiculturalismo desarrollado en América Latina para alcanzar la justicia entre culturas. La bibliografía sobre el concepto de interculturalidad es extensa y abarca distintos campos del conocimiento, la filosofía, la antropología, la pedagogía, la política y el derecho, entre otros. Para los fines de este trabajo se toman como referencia las perspectivas políticas, particularmente los trabajos de Catherine Walsh y de Fidel Tubino.

5 Víctor Torres, La acción pública intercultural, Abya Yala, Quito (2010). 
sus postulados. Trata de conciliar la tolerancia y la libertad individual, propios de la filosofía liberal, con los derechos diferenciados en función del grupo, imprescindibles para garantizar justicia e igualdad entre culturas. El interculturalismo, por su parte, asume varios postulados de Kymlicka, como la necesidad de derechos diferenciados. Pero también formula críticas de tipo metodológico, normativo y práctico, con miras a alcanzar una justicia sustancial, más que formal, entre culturas, que ataque las causas económicas y sociales de la desigualdad, así como el diálogo, el respeto y la convivencia, más allá de la tolerancia y la coexistencia entre ellas.

\section{A. La justicia cultural en el multiculturalismo de Kymlicka}

Para Kymlicka resulta inadmisible el que los comunitaristas, partiendo con frecuencia de nociones esencialistas de la cultura y de la identidad, impidan que los individuos puedan cuestionar las nociones de vida buena de sus culturas, pues de esa manera vulneran el principio liberal de libertad individual ${ }^{6}$. Para el filósofo canadiense ${ }^{7}$, los individuos pueden libremente someter a revisión los fines o concepciones de vida buena de sus culturas y elegir aquellos que consideren mejores. Pueden elegir dentro de su propia cultura, pero también integrar lo que admiren de otras culturas: "[...] desde cualquier perspectiva liberal, es bueno que las culturas aprendan las unas de las otras. Los liberales no pueden defender una noción de cultura que considere que el proceso de interacción y de aprendizaje de

6 La discusión entre la perspectiva liberal y la comunitarista está bien documentada. Ver Angelo Papachini, Comunitarismo, liberalismo y derechos humanos, en: F. Cortés \& A. Monsalve, Eds., Liberalismo y comunitarismo. Derechos humanos y democracia, 231-261, Edicions Alfons El Magnánim, Valencia (1996); Óscar Mejía \& Daniel Bonilla, El paradigma consensual-discursivo del derecho como instrumento conciliador de la tensión entre multiculturalismo comunitarista y liberalismo multicultural, en Multiculturalismo y los derechos de las minorías culturales, Res-Pública - Universidad de Antioquia, Murcia, 83-117 (1999). Para una reconstrucción del enfoque de Kymlicka ver: Daniel Bonilla, La ciudadanía multicultural y la política del reconocimiento, Bogotá, Universidad de los Andes (1999). Kymlicka realiza una síntesis inteligente del camino recorrido hasta la formulación de su enfoque en: Will Kymlicka, El Nuevo debate sobre los derechos de las minorías, en: Ferrán Requejo, Ed., Democracia y pluralismo nacional, Ariel, Barcelona, 25-48 (2002).

7 Will Kymlicka, Ciudadanía multicultural, 149. 
otras culturas constituye una amenaza a la 'pureza' o a la 'integridad' en lugar de una oportunidad de enriquecimiento"s.

Pero Kymlicka tampoco acepta que los liberales se nieguen a promover un trato diferente a los individuos miembros de grupos en desventaja ${ }^{9}$. Por eso, se orienta a conciliar los derechos individuales con los derechos específicos en función del grupo para hacer posible la equidad entre culturas. Ello es necesario por la emergencia de crecientes disputas entre los grupos culturales pertenecientes a un mismo Estado nación, sobre derechos lingüísticos, autonomía regional, representación política o símbolos nacionales ${ }^{10}$. En los regímenes democráticos, tales cuestiones terminan por decidirlas siempre las mayorías, por lo que se cometen injusticias con las minorías ${ }^{11}$.

La posición de los liberales se explica por su noción restringida de ciudadanía. De acuerdo con Requejo ${ }^{12}$, la ciudadanía se ha entendido como el estatus de igualdad de todo individuo como miembro de la comunidad política. Esta concepción ha sido revisada en varias oportunidades, como cuando se incluyeron las demandas democratizadoras en la primera posguerra, o cuando se establecieron los derechos sociales y el Estado de bienestar en la

8 Ibíd., 145.

9 Cuando se trata de discutir la regulación de derechos de grupo, la versión liberal estándar se opone a ellos en términos del individualismo. Solo los individuos son portadores de derechos, no los grupos. En la base de esta concepción se encuentra una visión sesgada de la universalidad: "Es decir, dichos derechos se consideran improcedentes porque no van dirigidos a todos los ciudadanos de ese estado particular, sino a un grupo de ellos. Creo que parte de las incomprensiones del liberalismo tradicional hacia los derechos de grupo se basa en que usa un lenguaje universalista referido a un grupo particular, los ciudadanos de un estado, en el que se da por sentada una identidad uniforme de ciudadanía pensada desde las premisas de un implícito nacionalismo de carácter estatalista. El resultado es un liberalismo que acusa de 'particularistas' $y$ ajenas a los 'intereses generales' las pretensiones de regular unos derechos de grupo de carácter nacional cuando éstos no coinciden con el particularismo del grupo hegemónico que el estado define como 'nacional'". Ferrán Requejo, Pluralismo, democracia y federalismo, 101. De esa forma, el liberalismo es el comunitarismo particular de las sociedades occidentales. En el interior de esas sociedades los liberales han impulsado valores e identidades particulares de carácter nacional en detrimento de los de colectividades minoritarias. "En nombre de un pretendido universalismo de base individual se laminan valores colectivos de grupos minoritarios en beneficio de otros valores, también colectivos, de los grupos mayoritarios. De hecho, todas las democracias han defendido un nacionalismo de estado. Y, a mi entender, esta es una realidad que vulnera el núcleo normativo de la perspectiva liberal en estados plurinacionales, cuando no recoge el pluralismo cultural interno de las distintas colectividades nacionales en la misma noción de ciudadanía democrática". Ibíd., 102.

10 Will Kymlicka, Ciudadanía multicultural, 13.

11 Ibíd., 18.

12 Ferrán Requejo, Pluralismo, democracia y federalismo, 99. 
segunda. El pluralismo cultural plantea la necesidad de otra revisión, que conciba la ciudadanía como estatus, pero también como identidad. En esta perspectiva, Kymlicka ${ }^{13}$ cuestiona el principio liberal que considera que para tramitar la diversidad cultural no son necesarios los derechos de grupo, pues atentarían contra la igualdad de estatus que comporta la ciudadanía individual. Según este principio, la identidad étnica o cultural es análoga a las creencias religiosas: quedan relegadas al ámbito de lo privado, donde pueden expresarse con libertad, pero no competen al Estado.

Para Kymlicka ${ }^{14}$, esa analogía es insostenible, pues el Estado puede ser neutral frente a las creencias religiosas pero no así frente a las identidades étnicas o nacionales, puesto que en una democracia, donde las mayorías deciden, el Estado termina por privilegiar en forma sistemática la cultura mayoritaria ${ }^{15}$. La posición de los liberales soslaya que los miembros de minorías nacionales están en desventaja en aspectos que no afectan a la mayoría ${ }^{16}$. Por lo tanto, la imparcialidad no demanda tratar todas las culturas como si fuesen iguales, sino darle trato diferenciado a lo que es diferente, procurando a las minorías nacionales las mismas oportunidades que a la mayoría. De esa forma, se consigue la equidad entre culturas y se alcanza una justicia cultural basada en el principio "todos los grupos nacionales tienen la posibilidad de mantenerse como cultura distinta, si así lo desean"17. Este principio justifica los derechos diferenciados en función del grupo con el objeto de compensar las desigualdades que ponen en situación desventajosa a los individuos pertenecientes a las culturas minoritarias. La ciudadanía multicultural implica que las personas se incorporan a la comunidad política como ciudadanos individuales pero también como miembros del grupo cultural con una identidad ${ }^{18}$.

Para fundamentar esos derechos, Kymlicka ${ }^{19}$ formula una tipología de la diversidad en el interior del Estado nación. De un lado, existe un modelo de "minorías nacionales", en el cual la diversidad

\footnotetext{
13 Will Kymlicka, Ciudadanía multicultural, 15-16.

14 Ibíd., 157.

15 Ibíd., 80.

16 Ibíd., 156

17 Ibíd., 60.

18 Ibíd., 240.

19 Ibíd., 25-26.
} 
cultural es consecuencia de la incorporación en el Estado de grupos que poseen un territorio y con anterioridad tuvieron autogobierno, por lo que demandan grados de autonomía para desarrollar su cultura. De otro, un modelo de "grupos étnicos", aquellos que son producto de la migración individual o familiar, y que, a diferencia de las minorías nacionales, no demandan el establecimiento de una sociedad paralela, sino que reivindican el reconocimiento de su identidad y un trato especial para integrarse a la cultura mayoritaria en igualdad de condiciones ${ }^{20}$.

En correspondencia con esa tipología, existen derechos diferenciados para cada caso. Los grupos étnicos tendrán derechos poliétnicos, como las medidas para erradicar la discriminación (acciones afirmativas), la exención de ciertas leyes o disposiciones que puedan contrariar los valores de su cultura o la subvención estatal de prácticas culturales, a fin de fomentar su integración a la cultura mayoritaria ${ }^{21}$. Las minorías nacionales, por su parte, reclaman derechos de autogobierno, autonomía política y jurisdicción territorial, para su autodeterminación en el interior del Estado nación ${ }^{22}$. Esas autonomías se complementan con derechos especiales de representación, sin los cuales se verían vulneradas, por órganos superiores de decisión como los parlamentos, las altas cortes o el ejecutivo ${ }^{23}$.

Para que estos derechos grupales no vulneren los derechos individuales, Kymlicka ${ }^{24}$ plantea una distinción entre "restricciones internas" y "protecciones externas". Las restricciones internas son reivindicaciones del grupo cultural en contra de sus miembros individuales, que tienen como función protegerlo del disenso interno. Las protecciones externas hacen referencia a reivindicaciones del grupo cultural frente a la sociedad englobante, que tratan de protegerlo del impacto de sus decisiones. Restricciones internas y protecciones externas contribuyen a salvaguardar la estabilidad del grupo, pero pueden usarse para vulnerar los derechos individuales.

Mediante las restricciones internas los grupos pueden aprovechar el poder estatal, conferido mediante derechos diferenciados,

20 Ibíd., 31.

21 Ibíd., 53.

22 Ibíd., 47.

23 Ibíd., 54-55.

24 Ibíd., 58. 
para coartar o restringir la libertad o autonomía de sus miembros individuales. Por ejemplo, obligándolos a realizar ciertas prácticas, vestirse de alguna forma o asistir a una iglesia determinada, o impidiendo otras, como negar la posibilidad de que las mujeres accedan a la educación superior ${ }^{25}$. Las protecciones externas no se refieren a la opresión de los individuos en el interior del grupo, sino a la injusticia entre grupos. Las protecciones de un grupo pueden funcionar como privilegios, ocasionando la segregación o la opresión de otros grupos, como en el apartheid o el régimen de castas indio. No obstante, las protecciones externas no necesariamente generan injusticias entre grupos, pues a priori no establecen una posición de dominio del grupo beneficiado con la protección sobre otros grupos. Por el contrario, pueden situarlos en mayor pie de igualdad al reducir "la medida en que el grupo más pequeño es vulnerable ante el grande" 26 . Por ello, para Kymlicka ${ }^{27}$ solo deben admitirse protecciones externas cuando fomenten la igualdad entre grupos, nunca cuando permitan que un grupo oprima a otros. Los derechos diferenciados en función del grupo no pueden permitir que un grupo oprima a otros o a sus miembros individuales ${ }^{28}$. En consecuencia, los liberales solo deben aprobar tales derechos si respetan la autonomía individual ${ }^{29}$. Deben apoyar algunas protecciones externas, pero rechazar las restricciones internas que limiten el derecho de los individuos a cuestionar sus prácticas tradicionales y autoridades ${ }^{30}$.

De esta forma, el filósofo canadiense conduce a una concepción de la justicia entre culturas basada en el reconocimiento de derechos diferenciados, de forma que los miembros individuales de las culturas minoritarias y mayoritarias tengan las mismas oportunidades.

\footnotetext{
25 Ibíd., 58-59.

26 Ibíd., 60.

27 Ibíd., 212.

28 Ibíd., 266.

29 Ibíd., 111.

30 Ibíd., 60.
} 


\title{
B. La crítica del multiculturalismo y el concepto de interculturalidad
}

En su sentido normativo más básico, la interculturalidad denota "una relación simétrica y de reconocimiento mutuo" 31 entre culturas. Aspira a una relación equitativa, de diálogo y mutuo aprendizaje entre culturas y se ha construido en una tensión crítica con el multiculturalismo. De acuerdo con Tubino ${ }^{32}$ :

Mientras que el multiculturalismo busca producir y produce sociedades paralelas, la interculturalidad busca producir sociedades integradas y relaciones simétricas entre las diversas culturas. Las políticas multiculturales evitan los desencuentros. Las politicas interculturales promueven los encuentros. El multiculturalismo promueve la tolerancia, el interculturalismo el diálogo. El multiculturalismo no erradica los prejuicios y los estereotipos negativos que contaminan las relaciones entre los diferentes. La interculturalidad busca erradicar los prejuicios que están en la base de la estigmatización social y la discriminación cultural.

Resaltando su carácter normativo o prescriptivo, Catherine Walsh ${ }^{33}$ confiere un significado aun más amplio a la interculturalidad:

\begin{abstract}
Mientras que lo "multi" apunta a una colección de culturas singulares sin relación entre ellos y en un marco de una cultura dominante, lo "pluri" típicamente indica una convivencia de culturas en el mismo espacio territorial aunque sin una profunda interrelación equitativa [...] La interculturalidad, en cambio, aún no existe. Es algo por construir. Va mucho más allá del respeto, la tolerancia y el reconocimiento de la diversidad; señala y alienta, más bien, un proceso y proyecto social político dirigido a la construcción de sociedades, relaciones y condiciones de vida nuevas y distintas. Aquí me refiero no sólo a las condiciones económicas sino también aquellas que tienen que ver con la cosmología de la vida en general, incluyendo los conocimientos y saberes, la memoria ancestral, y la relación con la madre naturaleza y la espiritualidad, entre otras.
\end{abstract}

De acuerdo a estas definiciones, puede afirmarse que el concepto de interculturalidad se construye con base en tres críticas al multi-

31 Mario Blaser, Bolivia: los desafíos interpretativos de la coincidencia de una doble crisis hegemónica, en P. Stefanoni \& H. Do Alto, Eds., Reinventando la nación en Bolivia. Movimientos sociales, Estado y poscolonialidad, Clacso-Plural, La Paz, 15 (2007).

32 Fidel Tubino, La praxis de la interculturalidad en los estados nacionales latinoamericanos, 3 Cuadernos Interculturales, No. 5, 94 (2005).

33 Catherine Walsh, Interculturalidad, plurinacionalidad y decolonialidad: las insurgencias politicoepistémicas de refundar el Estado, Tabula rasa, No. 9, 140 (2008). 
culturalismo, aunque asume varios de sus postulados. Una crítica metodológica, que cuestiona la asunción del multiculturalismo, según la cual las relaciones de desigualdad entre culturas están determinadas por su tamaño, siendo las mayoritarias siempre las culturas dominantes. Una crítica de los horizontes normativos, que intenta ir más allá de la coexistencia y la tolerancia entre culturas, implícitos en el enfoque de Kymlicka, para construir el diálogo, el respeto y la convivencia entre ellas. Y una crítica de los medios, que trata de ir más allá de la justicia formal provista por el reconocimiento de derechos de grupo, para avanzar hacia una justicia sustancial, que ataque las causas sociales y económicas de la desigualdad entre culturas y permita la construcción de una cultura política común y diversa.

\section{La crítica metodológica}

En primer lugar, el interculturalismo plantea una crítica metodológica al enfoque de Kymlicka. Como se ha visto, el filósofo canadiense supone que el problema de la desigualdad entre culturas se explica por su tamaño. En las democracias, las culturas minoritarias siempre serán vulnerables ante las decisiones de la mayoría. Sin embargo, no en todos los casos es así. Por eso, el interculturalismo hace énfasis en las relaciones de dominación y subalternidad entre culturas, con independencia de su tamaño.

A este respecto, Walsh ${ }^{34}$ retoma el concepto de "colonialidad del poder", planteado por el sociólogo peruano Aníbal Quijano, con el fin de conceptualizar la desigualdad entre culturas propia del contexto latinoamericano ${ }^{35}$. Tal categoría alude a un patrón de poder fundado en la idea de raza como medio de jerarquización social, legado de la dominación colonial. En América Latina existen sociedades pluriculturales que no están representadas por sus

34 Catherine Walsh, Interculturalidad, Estado, Sociedad. Luchas (de)coloniales de nuestra época, Universidad Andina Simón Bolívar - Abya Yala, Quito, 28 (2009).

35 La categoría de colonialidad del poder se distingue de la de colonialismo porque no hace referencia al dominio de un Estado sobre territorios ultramarinos, sino a un complejo dispositivo de poder heredado de la Colonia y sustentado en la estratificación de la población según criterios como el de raza. Aníbal Quijano, Colonialidad del poder y clasificación social, XI Journal of World-Systems Research, No. 2, 342-386 (2000).

Para una presentación didáctica del concepto ver Eduardo Restrepo \& Axel Rojas, Inflexión decolonial: fuentes, conceptos y cuestionamientos, Instituto Pensar Pontificia Universidad Javeriana - Universidad del Cauca, Popayán, 91-114 (2010). 
Estados nación, pues estos se presentan como monoculturales. Ello explica por qué las élites blancas o mestizas se ubican en los estratos sociales altos, mientras que para los indígenas y afrodescendientes, antiguas "castas" de la Colonia, están reservados los más bajos. De esa forma, existen países donde la colonialidad del poder coincide con el carácter mayoritario de la cultura dominante, como pueden ser los casos de Ecuador o Colombia, gracias al predominio de la población mestiza. No obstante, también hay países donde la cultura dominante es minoritaria, como en Bolivia o Guatemala, donde las mayoritarias culturas indígenas han sido subalternizadas por una reducida élite blanca o mestiza.

De otro lado, el interculturalismo, inspirado en América Latina, cuestiona la distinción entre minorías nacionales y grupos étnicos que establece Kymlicka. Para el filósofo canadiense ${ }^{36}$, las minorías nacionales poseen una "cultura institucional" - costumbres, memoria colectiva, lengua - y un territorio, mientras que los grupos étnicos provienen de la inmigración individual o familiar. En consecuencia, las primeras tienen derecho a protecciones externas para mantener su cultura diferenciada, en tanto que los grupos étnicos solo tienen derechos poliétnicos para asegurar su integración a la cultura mayoritaria en condiciones de igualdad ${ }^{37}$. Sin embargo, en América Latina existen grupos que se identifican como naciones o pueblos, aunque no satisfagan esos criterios. Por ejemplo, en varios países los afrodescendientes se identifican como pueblos o culturas así no tengan territorios ni idiomas propios. Las comunidades afroecutorianas y afrocolombianas reclaman la pertenencia a un territorio, la "Gran Comarca" en la Costa Pacífica, desde el Darién en Panamá hasta el norte de Esmeraldas en Ecuador. En Bolivia, el pueblo moxeño reclama un territorio y se autoconcibe como pueblo, pese a no poseer idioma propio. En Ecuador, los kichwas, si bien no tienen un territorio delimitado, pues sus asentamientos se confunden con los pobladores mestizos de la Sierra, se conciben

36 Will Kymlicka, Ciudadania multicultural, 36.

37 Kymlicka establece una diferencia normativa entre minorías nacionales y grupos étnicos. A su juicio, las minorías nacionales podrían conservar su "cultura societal" porque, dado que el tránsito entre culturas es difícil y costoso, la opción de abandonarla es un derecho y no una obligación. Ibíd., 142. Pero este postulado no es extensible a los "grupos étnicos", pues los inmigrantes han decidido abandonar su cultura societal y, por tanto, renunciado a su derecho. El problema de justicia es hacer que la cultura mayoritaria sea hospitalaria salvaguardando sus derechos a expresar su identidad. Ibíd., 136-137. 
como una nacionalidad indígena. Así pues, la tipología que establece Kymlicka no es aplicable a todos los casos latinoamericanos. Por lo tanto, el interculturalismo puede justificar una ciudadanía diferencial en casos de grupos étnicos que, como en los casos mencionados, no son producto de la inmigración, y que sin tener un territorio o idioma se reclaman como pueblos o naciones.

\section{La crítica de los fines}

Una segunda crítica al multiculturalismo tiene que ver con su contenido prescriptivo. Tanto el multiculturalismo de Kymlicka como el interculturalismo latinoamericano aspiran a establecer relaciones equitativas entre culturas. Sin embargo, el interculturalismo enfatiza en la necesidad del diálogo entre ellas, los intercambios y el aprendizaje mutuo. Para Walsh ${ }^{38}$, la interculturalidad es "el contacto e intercambio entre culturas en términos equitativos; en condiciones de igualdad"39. El intercambio es un aprendizaje y comunicación permanente entre los grupos e individuos que forman las culturas y entre sus distintas racionalidades, valores, saberes y tradiciones. Tal intercambio está orientado al respeto mutuo y al desarrollo de los grupos e individuos más allá de las diferencias culturales. Las relaciones entre culturas siempre tienen lugar, se trata de que se desarrollen en condiciones de igualdad para que los valores de la cultura dominante no se impongan sobre los de la subordinada. Así planteada, la interculturalidad es parte de un proyecto descolonizador, que propugna por eliminar toda desigualdad entre culturas $^{40}$. El objetivo no es terminar con el conflicto, pues este es inevitable y es un motor de enriquecimiento cultural. Dado que los seres humanos comparten infinidad de aspectos ${ }^{41}$, se trata de gestionar el diálogo y orientarlo al desarrollo individual y colectivo.

38 Catherine Walsh, Interculturalidad, Estado, Sociedad. Luchas (de)coloniales de nuestra época, Universidad Andina Simón Bolívar - Abya Yala, Quito, 49 (2009).

39 Ibíd., 14.

40 Ibíd., 54. Josef Esterman, Colonialidad, descolonización e interculturalidad. Apuntes desde la filosofía intercultural, en Interculturalidad crítica y descolonización. Fundamentos para el debate, Instituto Internacional de Integración del Convenio Andrés Bello, La Paz, 52 (2009).

41 Galo Ramón, ¿Plurinacionalidad o interculturalidad en la Constitución?, en: Alberto Acosta \& Esperanza Martínez, Comps., Plurinacionalidad: democracia en la diversidad, Abya Yala, Quito, 135 (2009). 
El multiculturalismo de Kymlicka apuesta por la tolerancia y la coexistencia entre culturas. En contraste, el interculturalismo latinoamericano propugna por construir relaciones de respeto mutuo y convivencia. La interculturalidad "no tiene la pretensión de asumir la perspectiva del otro sino de permitir que la diferencia intervenga en uno, abriendo así nuevas perspectivas interculturales de vivir 'con' o 'con-vivir"' 42 . La convivencia y el aprendizaje mutuo no significan disolver las diferencias de los interlocutores en una síntesis única, tipo mestizaje ${ }^{43}$. Pero tampoco implica una situación donde las culturas coexisten y se toleran, sin ningún tipo de contacto o con contactos limitados, sin convivir. En consecuencia, el interculturalismo asume que los derechos diferenciados en función del grupo son necesarios para alcanzar la equidad entre culturas, pero se requiere ir más allá de la coexistencia y la tolerancia, pues no necesariamente implican diálogo entre culturas, como sí lo hacen los valores de la convivencia y el respeto.

Tolerar es "soportar lo diferente" ". Implica que el intercambio y el diálogo entre culturas, así como la misma existencia del otro, no se perciben como un bien en sí mismos, sino como un mal menor. En últimas, supone que lo deseable sería no tener que coexistir con el otro. Adoptando el valor de la tolerancia, las culturas pueden coexistir y los conflictos entre ellas pueden hacerse más manejables, pero lo hacen de forma aislada, sin convivir. En contraste, el respeto supone otra forma de relación con el otro. En este caso, la existencia del otro y el intercambio con él son percibidos como un fin en sí mismos y, por tanto, son deseables ${ }^{45}$. De esa forma, el respeto coadyuva a la convivencia entre culturas y al logro del re-

42 Catherine Walsh, Interculturalidad, Estado, Sociedad, 15.

43 La interculturalidad "sugiere un proceso activo y permanente de negociación e interrelación donde lo propio y particular no pierdan su diferencia, sino que tengan la oportunidad y capacidad para aportar desde esta diferencia a la creación de nuevas comprensiones, convivencias, colaboraciones y solidaridades. Por eso la interculturalidad no es un hecho dado sino algo en permanente camino, insurgencia y construcción”. Catherine Walsh, Interculturalidad, plurinacionalidad y decolonialidad, 141.

44 Fidel Tubino, Interculturalizando el multiculturalismo, Monografías CIDOB, Barcelona, 2 (2003).

45 "No basta con un respeto que solo signifique el derecho declarado a existir. Semejante "respeto" sería muy limitado y con razón algunos podrían considerarlo engañoso. Estamos hablando de un respeto que signifique tomar en serio las diferentes culturas, dando la oportunidad a quienes las practican de desarrollarlas en interacción con otras culturas". Juan Ansion, La interculturalidad y los desafíos de una nueva forma de ciudadanía, en Educar en ciudadanía intercultural, Universidad de la Frontera - Pontificia Universidad Católica del Perú, Lima, 44-45 (2007). 
conocimiento. Como afirma Tubino ${ }^{46}$, "reconocer al otro es respetar su autonomía, es percibirlo como valioso. Pero la valoración a priori del otro es un falso reconocimiento. La gente merece y desea respeto, no condescendencia. El verdadero reconocimiento es a posteriori, se da en la experiencia del encuentro con el otro. Pero sólo es posible en relaciones auténticamente simétricas y libres de coacción".

Aunque estas críticas están orientadas al contenido normativo del multiculturalismo, tienen implicaciones prácticas sobre las políticas públicas, como adelante se verá, y sobre aspectos como los derechos de autogobierno conferidos a las minorías culturales o el pluralismo jurídico. Respecto del autogobierno, en la perspectiva multicultural, protecciones externas y restricciones internas hacen que los grupos culturales con derechos de autogobierno estén facultados para elegir sus propias autoridades según sus concepciones en sus circunscripciones territoriales, siempre y cuando no contraríen los valores liberales u opriman a sus miembros individuales. Ello implica tolerar esas prácticas y concepciones políticas, pero no necesariamente ponerlas a dialogar o convivir con las de la cultura mayoritaria. En contraste, para el interculturalismo se trata de que los usos y costumbres de la cultura subordinada entren en diálogo equitativo y en convivencia con los de la dominante ${ }^{47}$. Para ello sería necesario no restringir en todos los casos los usos y costumbres de las culturas subordinadas a sus circunscripciones territoriales. Se podría, por ejemplo, facilitar la adopción de algunos de sus usos en instancias donde se encuentren representadas las distintas culturas, parlamentos, cortes, de tal forma que puedan convivir con los de la cultura dominante en procesos de elección o toma de decisiones.

Algo similar se presenta respecto del pluralismo jurídico. Para el multiculturalismo, los sistemas normativos de las culturas subordinadas pueden funcionar en forma autónoma siempre que respeten la autonomía individual, pero solo en el interior de sus circunscripciones territoriales ${ }^{48}$. Así, los sistemas normativos de las distintas culturas coexisten, pero no conviven. En cambio, desde

46 Fidel Tubino, Interculturalizando el multiculturalismo, 10.

47 Catherine Walsh, Interculturalidad, Estado, Sociedad. Luchas (de)coloniales de nuestra época, Universidad Andina Simón Bolívar-Abya Yala, Quito, 81 (2009).

48 Camilo Borrero, ${ }_{\zeta M}$ Multiculturalismo o interculturalidad?, en D. Carrillo \& N. Patarroyo, Eds., Derecho, interculturalidad y resistencia étnica, Universidad Nacional de Colombia, Bogotá, 68 (2009). 
la perspectiva intercultural, se trata de alcanzar, hasta donde sea posible, el funcionamiento igualitario de los distintos órdenes ${ }^{49}$. La convergencia de distintas prácticas y lógicas debe sustentar la "interculturalidad jurídica" ${ }^{50}$. El interculturalismo no plantea una regla universal, como la de no aceptar restricciones internas que propone el multiculturalismo, a fin de gestionar los conflictos entre los distintos sistemas de normas. No obstante, se conocen prácticas que apuntan a desarrollar ese ideal. Por ejemplo, los "traductores culturales" para que el derecho no se aplique desde una perspectiva cultural dominante. Incluso, para garantizar que los delitos se analicen a partir del contexto cultural y que los valores de las distintas culturas entren en diálogo para tomar una decisión, en Canadá se han puesto en práctica los "círculos de justicia", donde el proceso de juzgamiento involucra jueces estatales y autoridades tradicionales indígenas en un proceso de diálogo cuyo objetivo es el consenso ${ }^{51}$.

\section{La crítica de los medios}

Para alcanzar la igualdad entre culturas, el multiculturalismo apuesta por una justicia formal, basada en el reconocimiento de derechos diferenciados. El interculturalismo, en contraste, apuesta por cambios estructurales para conseguir no solo la equidad sino también el diálogo y el aprendizaje mutuo. Según Tubino ${ }^{52}$, el interculturalismo no parte del diálogo, sino que se pregunta por sus condiciones de posibilidad. La convivencia entre culturas en términos igualitarios no es un problema de voluntad subjetiva únicamente, sino sobre todo de constricciones estructurales, políticas, económicas y sociales, que condicionan tales relaciones ${ }^{53}$. Por lo tanto, es necesario ir más allá del reconocimiento de las diferencias y promover cambios estructurales, redistribución del poder político

49 Catherine Walsh, Interculturalidad, Estado, Sociedad, 172.

50 Catherine Walsh, El pluralismo jurídico: el desafío de la interculturalidad, Novamérica, No. 133, 36 (2012).

51 Catherine Walsh, Interculturalidad, Estado, Sociedad, 180.

52 Fidel Tubino, Del interculturalismo funcional al interculturalismo crítico, en Rostros y fronteras de la identidad, Universidad Católica de Temuco, 158 (2004).

53 Jorge Viaña, Luis Claros \& Marcelo Sarzuri, Presentación, en Interculturalidad crítica y descolonización. Fundamentos para el debate, Instituto Internacional de Integración del Convenio Andrés Bello, La Paz, 7 (2009). 
y económico, que ataquen las causas de la desigualdad entre culturas $^{54}$. Ello implica una reinvención del Estado, la democracia y el modelo de desarrollo económico ${ }^{55}$. Así pues, a diferencia del multiculturalismo que apuesta por una justicia cultural sin preguntarse por su relación con la justicia social, el interculturalismo apunta a articular las demandas por la igualdad social o redistribución, con las reivindicaciones de reconocimiento de la diferencia ${ }^{56}$.

Pero para el interculturalismo el diálogo entre culturas no solo requiere transformaciones socioeconómicas, sino también culturales. Se necesita un cambio en la cultura pública, pues el diálogo entre culturas en condiciones equitativas requiere un espacio común ${ }^{57}$. Siguiendo a Tubino ${ }^{58}$, el trámite de los inevitables conflictos entre culturas requiere un espacio público abierto al diálogo. A diferencia de la perspectiva multicultural, que considera que la cultura pública es la de la cultura mayoritaria, la interculturalidad propugna por la construcción de un espacio neutro y abierto a las diferencias: "la primera tarea de las democracias multiculturales consiste en crear espacios públicos interculturales en los que se den cita la diversidad de racionalidades para deliberar en común y llegar a generar respuestas $y$ acciones concertadas ante los problemas propios y ajenos" 59 .

Estos cambios no solo son necesarios para que cada cultura mantenga su diferencia si así lo quiere, sino sobre todo para el reconocimiento del otro como sujeto: como igual y al mismo tiempo como diferente ${ }^{60}$. En última instancia, este es el criterio de justicia del interculturalismo. Como permite inferir el estudio de Todorov ${ }^{61}$, cuando la otra cultura se reconoce solamente como igual a la propia, se puede caer en el desconocimiento de su particularidad y en su asimilación (asimilacionismo). Pero cuando se reconoce únicamente

54 Fidel Tubino, El interculturalismo frente a los desafíos del pluralismo jurídico, en Caminos para la inclusión en la educación superior, Fondo Editorial Fundación Equitas, Lima, 195-196 (2007).

55 Jorge Viaña, Reconceptualizando la interculturalidad, en Construyendo interculturalidad crítica, Convenio Andrés Bello, La Paz, 11-12 (2010).

56 Nancy Fraser, Iustitia interrupta, Universidad de los Andes, Bogotá, 18 (1997).

57 Boaventura de Souza Santos, Las paradojas de nuestro tiempo y la plurinacionalidad, en: Alberto Acosta \& Esperanza Martínez, Comps., Plurinacionalidad: democracia en la diversidad, Abya Yala, Quito, 37-38 (2009).

58 Fidel Tubino, Del interculturalismo funcional al interculturalismo crítico, 152.

59 Ibíd., 152.

60 Catherine Walsh, Interculturalidad, Estado, Sociedad, 45.

61 Tzvetan Todorov, La conquista de América. El problema del otro, Siglo XXI, México, 293 (2010). 
como diferente a la propia, se puede caer en una concepción de superioridad o de desigualdad entre culturas. Esto implica que es necesario ir más allá del criterio multicultural de permitir que las culturas mantengan su diferencia si así lo desean, porque ello es compatible con la desigualdad entre culturas. Una cultura subordinada puede mantener su diferencia, sin que ello implique una relación equitativa con las otras, como en el apartheid o el régimen de castas indio. La justicia implica reconocer la otra cultura como igual y, en forma simultánea, como diferente a la propia.

Estas críticas no implican que multiculturalismo e interculturalismo sean mutuamente excluyentes. El interculturalismo también adopta la necesidad de derechos diferenciados en función del grupo, pero pretende radicalizar este criterio de justicia articulándolo a la justicia social. Los valores del interculturalismo, el respeto y la convivencia, el diálogo y el aprendizaje mutuo, además del reconocimiento del otro como sujeto, permiten distinguir las acciones afirmativas de lo que serían las políticas públicas interculturales.

\section{ACCIÓN ESTATAL Y JUSTICIA CULTURAL}

Las acciones afirmativas complementan los derechos diferenciados para alcanzar la justicia entre culturas. Pero, aunque son necesarias para la equidad entre culturas, son insuficientes para alcanzar los ideales de la interculturalidad. Las políticas interculturales, en contraste, persiguen el diálogo, el respeto y la convivencia entre culturas, y propugnan por atacar las causas estructurales que producen la desigualdad entre ellas.

\section{A. Las acciones afirmativas}

Con las acciones afirmativas nos encontramos en el terreno de las políticas públicas ${ }^{62}$. India fue el primer país en implementar acciones afirmativas para mejorar la suerte de los denominados "intocables" ${ }^{6}$. En los Estados Unidos se implementaron a partir

62 Este tipo de políticas se conocen como "políticas de las diversidades". Ver: André-Noël Roth \& Maguemati Wabgou, Las políticas públicas de las diversidades. Identidades y emancipación, Universidad Nacional de Colombia, Bogotá (2009).

63 Catherine Walsh, Acción afirmativa en perspectiva afroreparativa en: J. Sánchez, V. Avendaño $\&$ D. Caicedo, Eds., Pueblos afrodescendientes y derechos humanos. Del reconocimiento a las 
de la década de los sesenta del siglo pasado, para hacer frente a las demandas de los movimientos sociales, en particular el movimiento por los derechos civiles ${ }^{64}$.

Existe una ardua discusión sobre el término que mejor designaría estas políticas, el concepto de "acción afirmativa" se prefiere a los de "discriminación positiva" o "discriminación a la inversa", porque estos son contradictorios, dado que una discriminación no puede ser positiva ${ }^{65}$. No obstante, existe un creciente consenso en cuanto a sus contenidos. Mosquera et ál. ${ }^{66}$, después de analizar distintas definiciones de la acción afirmativa, arriban a una concepción según la cual tales acciones son medidas de carácter temporal implementadas por el Estado para tratar desigualdades históricamente acumuladas, garantizar la igualdad de oportunidades o compensar costos provocados por la discriminación de determinados grupos, por motivos étnicos, religiosos, sexuales o de género, entre otros. Sus principales características pueden definirse del siguiente modo:

Primero, la idea es favorecer la integración de los individuos o grupos discriminados en igualdad de condiciones a la sociedad. De ahí su carácter temporal y de corto plazo, pues se supone que en algún momento, cuando estos sujetos se integren y se supere la situación de discriminación, dejarán de ser necesarias. Pretenden avanzar hacia una sociedad "ciega en materia de color" o pertenencia étnica, donde tales acciones no serían necesarias ${ }^{67}$. Los argumentos que las soportan están basados en la justicia distribu-

acciones afirmativas, Ministerio de Justicia, Derechos Humanos y Cultos del Ecuador-Oficina del Alto Comisionado de las Naciones Unidas para los Derechos Humanos, Quito, 213 (2011).

64 Olivia Cortez, Acciones afirmativas para afrodescendientes: ¿un reconocimiento de justicia o redistribución de recursos?, en: J. Sánchez, V. Avendaño \& D. Caicedo, Eds., Pueblos afrodescendientes y derechos humanos. Del reconocimiento a las acciones afirmativas, Ministerio de Justicia, Derechos Humanos y Cultos del Ecuador-Oficina del Alto Comisionado de las Naciones Unidas para los Derechos Humanos, Quito, 285 (2011).

65 Pastor Murillo, Las medidas de acción afirmativa o medidas especiales: para reparar las injusticias históricas y la discriminación, en: J. Sánchez, V. Avendaño \& D. Caicedo, Eds., Pueblos afrodescendientes y derechos humanos. Del reconocimiento a las acciones afirmativas, Ministerio de Justicia, Derechos Humanos y Cultos del Ecuador - Oficina del Alto Comisionado de las Naciones Unidas para los Derechos Humanos, Quito, 150-151 (2011).

66 Claudia Mosquera, Margarita Rodríguez \& Ruby León, Las acciones afirmativas como medio de inclusión social. Énfasis conceptuales, polémicas frecuentes y experiencias de implementación en algunos países, en: C. Mosquera \& R. León, Eds., Acciones afirmativas y ciudadanía diferenciada étnico-racial negra, afrocolombiana, palenquera y raizal, Universidad Nacional de Colombia, Bogotá, 76 (2009).

67 Will Kymlicka, Ciudadanía multicultural, 16-17. 
tiva, persiguen la igualdad de oportunidades según el principio de equidad social ${ }^{68}$.

Segundo, en un sentido similar a la justificación que Kymlicka acuña para los derechos diferenciados en función del grupo, las acciones afirmativas tratan de forma desigual a los grupos e individuos, para compensar, eliminar o cambiar las prácticas que conllevan a la desigualdad y la discriminación y asegurar la igualdad ${ }^{69}$. Sin embargo, no pueden confundirse con políticas para erradicar la pobreza o conseguir una igualdad material sustancial, son medidas para asegurar la igualdad de oportunidades.

Tercero, y en consecuencia, su meta es conseguir la igualdad en el acceso a bienes y servicios de las poblaciones discriminadas, de tal forma que se les garanticen los mismos derechos que al resto de la sociedad. Para ello comprenden incentivos que tratan de disminuir las desventajas sociales, políticas y económicas como las becas, cuotas o subvenciones, que igualmente realizan un tratamiento desigual para favorecer el grupo desfavorecido ${ }^{70}$. En tal sentido, se rigen por criterios primordialmente cuantitativos.

Finalmente, en algunos casos están sustentadas en un argumento de justicia reparativa. Desde esta perspectiva, su función es compensar o revertir formas de discriminación que afectaron en el pasado a determinadas poblaciones, como los afrodescendientes o los indígenas ${ }^{71}$. De acuerdo con Walsh ${ }^{72}$, la justicia reparativa implica aceptar que el racismo y la discriminación existen en el presente, enraizados en el Estado. Por tanto, supone reconocer que hubo y hay discriminación, y hacer todo lo posible por impedir su reproducción y/o repetición. La perspectiva reparativa "no solo se preocupa con [sic] la inclusión de sujetos tradicionalmente excluidos, sino también con la necesidad de remediar, enfrentar y transformar el orden de desigualdad e inequidad histórico-social"'73.

68 Claudia Mosquera, Margarita Rodríguez y Ruby León, Las acciones afirmativas como medio de inclusión social, 71.

69 Olivia Cortez, Acciones afirmativas para afrodescendientes, 285-286.

70 Claudia Mosquera, Margarita Rodríguez \& Ruby León, Las acciones afirmativas como medio de inclusión social, 81.

71 Rita Segato, Racismo, discriminación y acciones afirmativas: herramientas conceptuales, en Educar en ciudadanía intercultural, Universidad de la Frontera - Pontificia Universidad Católica del Perú, 82-83 (2007).

72 Catherine Walsh, Acción afirmativa en perspectiva afroreparativa, 227.

73 Ibíd., 207. 
Las acciones afirmativas obtienen su legitimidad desde distintas perspectivas. Por ejemplo, para $\mathrm{Segato}^{74}$, en su favor existen cuatro posturas que no siempre guardan concordancia entre sí: i) una postura "socialista y distributiva" que busca suprimir las desigualdades; ii) una "razón neoliberal" que persigue la inclusión de nuevos grupos en el mercado; iii) una "razón reparadora", que se orienta a hacer que el Estado repare los daños causados en el pasado por la esclavitud y el trabajo servil; y iv) un argumento pluralista, que apuesta por la construcción de una nación plural y con equidad entre los pueblos que la habitan. Sin embargo, estas acciones también han recibido críticas:

Primero, atentan contra el principio de igualdad y universalidad de la ciudadanía moderna. Desde esa perspectiva, las acciones afirmativas instauran privilegios que no son compatibles con la ciudadanía, pensada como estatus únicamente y pasando por alto la pertenencia cultural del ciudadano, pues se considera que el Estado debe ser neutral frente a problemas étnicos o culturales, considerados parte de la esfera privada ${ }^{75}$. Como sostiene Benavides $^{76}$, "desde una perspectiva liberal clásica se diría que basta con establecer la igualdad ante la ley, por lo que las políticas de acción afirmativa no serían necesarias, ya que una vez los sujetos tienen igualdad de oportunidades es el mérito el que comienza a determinar la posición de cada uno en la sociedad". Sin embargo, esta crítica no tiene en cuenta la necesidad de dirigir la acción del Estado en forma diferencial para garantizar mayor igualdad entre grupos, como defiende Kymlicka.

Segundo, pueden atentar contra el principio del mérito. Las acciones afirmativas asignan al individuo una responsabilidad en el presente por los hechos del pasado y le atribuyen una carga injusta a quienes no resultan beneficiados, de forma que "la elección de los sujetos sobre la base del mérito propia del liberalismo clásico debe ser necesariamente ciega a las condiciones materiales y a la historia"77.

74 Rita Segato, Racismo, discriminación y acciones afirmativas, 83.

75 Farid Benavides, La democracia liberal y el reto intercultural, en: D. Carrillo \& N. Patarroyo, Eds., Derecho, interculturalidad y resistencia étnica, Universidad Nacional de Colombia, Bogotá, 136 (2009).

76 Ibíd., 133-134.

77 Ibíd., 137. 
Empero, de acuerdo con Mosquera et ál. ${ }^{78}$, tal argumento no tiene en cuenta que el mérito no es algo natural ni neutro, sino que tiene unas raíces estructurales. Por ejemplo, si bien la inteligencia es un atributo universal de los seres humanos, el destacarse y tener méritos depende de distintas dotaciones de partida, capitales culturales o niveles de ingreso que, a su vez, dependen de que exista igualdad de oportunidades. En otras palabras, el mérito no se puede abstraer del hecho de que en la sociedad no existe igualdad de oportunidades. La acción afirmativa es un reconocimiento de que el mérito no necesariamente funciona como mecanismo para conseguir la igualdad y, por ende, es necesario garantizar la igualdad de oportunidades ${ }^{79}$.

Tercero, se acusa a las acciones afirmativas de ser discriminatorias en dos sentidos. Por una parte, al reforzar los estereotipos de los grupos a los que pretende beneficiar. Por ejemplo, para subsanar la discriminación racial, toman la raza como criterio focalizador de poblaciones, aumentando los efectos de lo que quieren aminorar ${ }^{80}$. Por otra, contribuyen a la discriminación porque suponen que los beneficiarios no pueden destacarse por sus propios medios ${ }^{81}$. Por tanto, en vez de fomentar la integración de las poblaciones beneficiadas, terminan por incrementar la estigmatización de los que son víctimas.

Cuarto, para algunos pueden motivar en las poblaciones discriminadas y victimizadas una preferencia por el asistencialismo estatal o un paternalismo, que puede desincentivar la lucha por el trabajo autónomo de los individuos ${ }^{82}$.

Finalmente, en el caso de los grupos étnicos o culturales, tales acciones no pueden reemplazar los derechos diferenciados en función del grupo. En la tipología de Kymlicka, las acciones positivas pueden contribuir a gestionar la pluralidad de los "grupos étnicos", con demandas de inclusión a la cultura mayoritaria, pero son ineficaces en el caso de las "minorías nacionales", pues estas

78 Claudia Mosquera, Margarita Rodríguez \& Ruby León, Las acciones afirmativas como medio de inclusión social, 85 .

79 Farid Benavides, La democracia liberal y el reto intercultural, 133-134.

80 Claudia Mosquera, Margarita Rodríguez \& Ruby León, Las acciones afirmativas como medio de inclusión social, 84 .

81 Pastor Murillo, Las medidas de acción afirmativa o medidas especiales, 252.

82 Ibíd., 252. 
plantean demandas de diferenciación y, como antes se mencionó, el criterio de justicia es permitir que se mantengan diferenciadas si así lo desean. En este caso, la igualdad plantea la necesidad de derechos diferenciados, que son sustancialmente distintos. El autogobierno, por ejemplo, no es una medida temporal ni un medio para hacer justicia a una forma de opresión que se debe eliminar, sino un derecho intrínseco y permanente ${ }^{83}$. Los derechos diferenciados tratan de proteger y favorecer el desarrollo de una cultura, mientras la acción positiva es una medida temporal para la integración del grupo beneficiado.

\section{B. Hacia las políticas interculturales}

En América Latina es frecuente la confusión entre acciones afirmativas y políticas interculturales, particularmente en el caso de la $\mathrm{EIB}^{84}$. Además, se ha considerado que la interculturalidad atañe solo al sector educación ${ }^{85}$. Empero, la interculturalidad debería fomentarse en otros sectores y erigirse en un enfoque de la acción estata $1^{86}$. Como sostiene Zapata-Barrero ${ }^{87}$, en el mundo contemporáneo las políticas públicas deben replantear el ideal universalista en que se soportó la intervención estatal en el siglo XX y no solo vincular criterios de redistribución, sino también de reconocimiento.

83 Will Kymlicka, Ciudadanía multicultural, 52.

84 Pese a su nombre, la EIB se formuló como una acción positiva integracionista, como educación bilingüe transicional, v. Catherine Walsh, Interculturalidad, Estado, Sociedad, 49. Trataba de mejorar el desempeño de los niños indígenas educándolos en sus lenguas nativas en los primeros años mientras aprendían el castellano. Para Yánez, es más correcto designarla como educación bicultural, pues supone que la cultura subordinada debe asimilar las pautas de la cultura dominante, empezando por el idioma: "El biculturalismo se concibe como la introducción de los conocimientos del mundo exterior y su asimilación, con miras a procurar el desarrollo cultural. Esta corriente tiende a superponer los conceptos de la sociedad dominante sobre los de la nativa". Consuelo Yánez, Educación indígena en Ecuador, Instituto de Capacitación Municipal - Ediciones de la Universidad Politécnica Salesiana, Quito, 71 (1996). En consecuencia, el problema de la educación no se asume como un problema exclusivo de los indígenas, sino que atañe a todos los sectores de la sociedad. Por eso, se concentró en zonas rurales pobres con alta población indígena y enfatizó en el trabajo lingüístico. Andrés Donoso, Rafael Contreras, Leonardo Cubillos y Luis Aravena, Interculturalidad y politicas públicas en Educación, XXXII Estudios pedagógicos, No. 1, 24 (2006).

85 Fidel Tubino, La praxis de la interculturalidad en los estados nacionales latinoamericanos, 3 Cuadernos Interculturales, No. 5, 84 (2005).

86 Andrés Donoso, Rafael Contreras, Leonardo Cubillos \& Luis Aravena, Interculturalidad y politicas públicas en Educación, 29.

87 Ricard Zapata-Barrero, Diversidad y política pública, Papeles, No. 104, $93-94$ (2008). 
Acción afirmativa y políticas interculturales no son mutuamente excluyentes. Por el contrario, las acciones afirmativas pueden contribuir a la equidad, al diálogo y a la convivencia entre culturas, además de complementar los derechos diferenciados en función del grupo. En algunos casos son las únicas alternativas posibles. Pero desde la perspectiva intercultural la eficacia de la acción afirmativa es ambigua. Existen coincidencias entre ambas, pues buscan corregir las inequidades entre grupos culturales desde una perspectiva sustancial, no solo formal como los derechos diferenciados. No obstante, las acciones afirmativas son necesarias pero no suficientes para alcanzar los ideales de la interculturalidad. Existen grandes diferencias metodológicas, normativas y prácticas:

\section{Lógica mayorías/minorías versus lógica dominación/ subalternidad}

Una primera diferencia tiene que ver con la orientación metodológica. Las acciones afirmativas están basadas en la distinción entre culturas mayoritarias y minoritarias. Al igual que el multiculturalismo de Kymlicka, suponen que siempre las culturas minoritarias son subordinadas y las mayoritarias dominantes. No obstante, como antes se mencionó, no siempre rige esta lógica. Existen casos en los que las culturas subordinadas son mayoritarias y las minoritarias dominantes, el criterio del tamaño no es determinante.

Siguiendo esta perspectiva, la acción afirmativa se basa en la focalización de la acción estatal. Su formulación e implementación requieren una clara identificación de la población objeto y de las características que la definen frente a la sociedad mayoritaria. Así, la acción afirmativa puede ser eficaz para conseguir la equidad entre los individuos miembros de grupos culturales discriminados donde sea posible focalizarlos, es decir, donde constituyan una minoría claramente identificable. Empero, su eficacia disminuye donde la mayoría de la población constituye una cultura subordinada, como Guatemala o Bolivia ${ }^{88}$. Ello se explica porque en estos casos no es posible focalizar claramente la población objeto y la acción afirmativa, por definición, no puede dirigirse a la mayoría de la población.

88 Claudia Mosquera, Margarita Rodríguez \& Ruby León, Las acciones afirmativas como medio de inclusión social, 104. 
En estos casos, se requieren otro tipo de medidas, orientadas al cambio estructural y a hacer equitativas las relaciones entre las culturas más que a integrar la cultura subordinada mayoritaria a los valores y formas de ser de la cultura dominante minoritaria.

\section{Más allá de las políticas correctivas}

Segundo, mientras que la acción afirmativa está orientada a corregir las consecuencias de la desigualdad entre culturas - la discriminación, la exclusión - , apuntando a mejorar la igualdad de oportunidades, las políticas interculturales apuestan por atacar las causas de tal desigualdad. Buscan corregir las constricciones políticas, económicas y sociales que soportan la desigualdad cultural. Ello permite articular las acciones por la justicia social con la necesidad del reconocimiento de la diferencia. De acuerdo con Tubino ${ }^{89}$ :

[...] el multiculturalismo anglosajón formula y busca remediar el problema de la injusticia cultural como si fuera un problema aislado y aislable. Por ello promueve la sustitución de las políticas asimilacionistas de los Estados nacionales monoculturales por políticas de reconocimiento de las identidades, sin cuestionar el modelo económico vigente. Por el contrario, el interculturalismo latinoamericano se plantea el problema de la injusticia como un problema ligado al problema de la pobreza y la exclusión social. La injusticia cultural, sostenemos, no es sino la otra cara de la injusticia económica. Por lo tanto, si la exclusión económica y la discriminación cultural son dos fenómenos estrechamente interconectados, entonces las políticas de reconocimiento deben estar forzosamente acompañadas de politicas redistributivas.

Allí donde la mayoría de la población constituye una cultura subordinada se requieren, más que acciones focalizadas, cambios estructurales que eliminen las causas de la inequidad. Así pues, es necesario complementar las acciones afirmativas con "acciones transformativas" $"$, que no solo ataquen las consecuencias de las

89 Fidel Tubino, El interculturalismo frente a los desafíos del pluralismo jurídico, 195-196.

90 El concepto de "acciones transformativas" es tomado de Nancy Fraser: "Con soluciones afirmativas a la injusticia me refiero a aquellas soluciones dirigidas a corregir los resultados inequitativos de los acuerdos sociales, sin afectar el marco general que los origina. Por soluciones transformativas, por el contrario, entiendo aquellas soluciones dirigidas a corregir los resultados inequitativos, precisamente mediante la reestructuración del marco general implícito que los origina. El punto esencial del contraste es resultados finales versus procesos que los generan, no el cambio gradual versus el apocalíptico". Nancy Fraser, Iustitia interrupta, 38. 
relaciones asimétricas entre culturas en el corto plazo sino sobre todo sus causas en el largo plazo ${ }^{91}$.

\section{Convivencia versus coexistencia}

Tercero, mientras las acciones afirmativas buscan la coexistencia, las políticas interculturales deben propender por la convivencia y el diálogo entre culturas. La acción afirmativa se enfoca en la igualdad entre grupos, descuidando el intercambio y el mutuo aprendizaje, ideales de la interculturalidad. Las acciones afirmativas son políticas principalmente para la equidad, no para la interculturalidad. Aunque mejoran la igualdad de oportunidades e introducen en la agenda pública temas de discriminación, generan tensiones que no necesariamente llevan a mejores formas de convivencia ${ }^{92}$.

En este sentido, pueden fortalecer prejuicios, porque no están orientadas a mejorar las relaciones entre culturas, y a menudo producen "islas étnicas" te en los grupos desfavorecidos o las culturas minoritarias, cuando el problema de la inequidad en las relaciones compete a ambos. La discriminación es una relación, si hay discriminados es porque hay discriminadores ${ }^{94}$. Para combatir la discriminación no solo se deben hacer políticas para los discriminados, sino también para los discriminadores. En fin, las acciones afirmativas son eficaces en promover el acceso de los excluidos a espacios de donde han sido discriminados. Sin embargo, ello no implica que la discriminación desaparezca. La hace visible, pero también puede reforzarla. Como afirma Fidel Tubino ${ }^{95}$, no es suficiente con fortalecer la identidad de los excluidos o discriminados, es necesario trabajar en mejorar las relaciones entre culturas:

91 Fidel Tubino, El nivel epistémico de los conflictos interculturales, 7 Revista electrónica construyendo nuestra interculturalidad, No. 6-7, 13 (2011).

92 Fidel Tubino, Las ambivalencias de las acciones afirmativas, en Educar en ciudadanía intercultural, Universidad de la Frontera - Pontificia Universidad Católica del Perú, Lima, 91 (2007). Por ejemplo, las políticas de educación para grupos étnicos, aunque reconozcan derechos en el marco de las políticas de reconocimiento, contribuyen a la reproducción de representaciones sobre poblaciones indígenas y negras. Axel Rojas \& Elizabeth Castillo, Multiculturalismo y políticas educativas en Colombia ¿̨interculturalizar la educación?, Revista Educación y Pedagogía, No. 48, 12 (2007).

93 Fidel Tubino, El interculturalismo frente a los desafios del pluralismo jurídico, 195.

94 Fidel Tubino, La praxis de la interculturalidad en los estados nacionales latinoamericanos, 90.

95 Fidel Tubino, Las ambivalencias de las acciones afirmativas, 96. 
Para que haya discriminación tiene que haber alguien que discrimina y alguien que es discriminado, alguien que estigmatiza y alguien que es estigmatizado. No basta con el fortalecimiento de la identidad de los discriminados para acabar con la discriminación; hay que cambiar las representaciones inconcientes sobre las cuales se han instalado patrones perversos de relación intercultural. $Y$ digo "perversos" porque se trata de relaciones que generan expectativas que no están en condiciones de satisfacer, que no pueden dar lo que ofrecen. Ofrecen reconocimiento y no lo otorgan ni a discriminados ni a discriminadores. Los discriminados no son reconocidos porque no son ni respetados ni valorados en su identidad. Y los que discriminan obtienen un reconocimiento forzado, falso, porque para ellos, los discriminados no son personas, son cosas, medios. Y el reconocimiento es, por definición, recíproco.

Se requiere una "interculturalidad para todos", que empieza por una educación realmente intercultural que incluya los miembros de las culturas dominantes ${ }^{96}$. No se trata de uniformizar las culturas, sino de preparar a sus miembros individuales para la interacción en condiciones de respeto recíproco. Ello pasa por la construcción de un espacio neutral de relación entre culturas, una cultura pública común abierta a todas las diferencias, cuyos criterios sean acordados con base en el diálogo y en el consenso entre los diferentes grupos culturales, más que en la imposición de los valores de la cultura dominante.

La ЕІB constituye un claro ejemplo de las limitaciones de la acción afirmativa para construir la convivencia entre culturas. De acuerdo con Donoso et ál. ${ }^{97}$, la EIB, al formularse como una educación para grupos específicos, tiene dificultades para que los estudiantes allí socializados convivan con otros grupos en otros contextos. El discurso de la educación intercultural trata de generar una pedagogía de la diversidad para permitir el desarrollo de los pueblos indígenas y una coexistencia social armónica. Pero en la práctica se focaliza en lo indígena y, en vez de buscar la coexistencia de las diversidades, pretende que los pueblos indígenas se integren a la sociedad nacional como ciudadanos abstractos. Un caso arquetípico es el de Ecuador. En 1992 se oficializó el modelo EIB gracias a las gestiones y presiones de las organizaciones indígenas. Sin embargo, la reforma (Ley 150 de 1992) mantuvo un concepto de educación restringido a los indígenas

96 Fidel Tubino, Del interculturalismo funcional al interculturalismo crítico, 154-155.

97 Andrés Donoso, Rafael Contreras, Leonardo Cubillos \& Luis Aravena, Interculturalidad y políticas públicas en Educación, 25-27. 
y más que un modelo de educación intercultural se creó uno dual, con una Dirección Nacional de Educación Bilingüe, a cargo de las organizaciones indígenas, y una Dirección Nacional de Educación Hispana para hispanohablantes ${ }^{98}$. Algo similar pasa con el modelo de las universidades interculturales, que en la práctica funcionan como universidades para indígenas. Alternativas interculturales podrían inspirarse en el "encuentro de saberes" implementado en la Universidad de Brasilia, que promueve el que maestros en saberes tradicionales impartan cátedra formal, con lo que entran a dialogar distintas lógicas de producción de conocimiento, como la oral y la escrita, además de especialistas en distintos saberes ${ }^{99}$.

\section{Políticas participativas}

Cuarto, las acciones afirmativas están orientadas "desde arriba". Por ello, pese a que contribuyen a disminuir las brechas sociales, crean vínculos de dependencia que coartan la autonomía de las personas ${ }^{100}$. Corren el riesgo de producir un paternalismo estatal, como antes se afirmó, o de producir "una cultura de la compasión

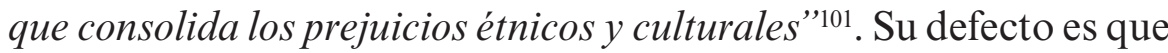
aunque aportan a la inclusión de los excluidos no los preparan para la interacción cultural, no forman ciudadanos capaces de desenvolverse en contextos culturales hostiles ${ }^{102}$.

Las políticas interculturales deben ser políticas participativas "desde abajo", que permitan un fortalecimiento de la sociedad civil y el diálogo entre las distintas culturas a fin de definir sus criterios. La interculturalidad, el diálogo en condiciones de respeto y convivencia con aprendizaje mutuo, son tanto un presupuesto de partida como una consecuencia de las políticas interculturales. El objetivo es que la formulación misma de las políticas convoque el diálogo intercultural, no que se formulen e implementen verticalmente

98 Eduardo Puente, El Estado y la interculturalidad en el Ecuador, Universidad Andina Simón Bolívar - Abya Yala - Corporación Editora Nacional, Quito, 15 (2005).

99 José Jorge De Carvalho, Los estudios culturales en América Latina: interculturalidad, acciones afirmativas y encuentro de saberes, Tabula Rasa, No. 12, 242 (2010).

100 Fidel Tubino, Interculturalizando el multiculturalismo, 6.

101 Fidel Tubino, Entre el multiculturalismo y la interculturalidad: más allá de la discriminación positiva, en: Norma Fuller, Ed., Interculturalidad y politica: desafíos y posibilidades, RDCSP, Lima, $72-73$ (2005).

102 Fidel Tubino, Las ambivalencias de las acciones afirmativas, 92. 
desde el Estado. Lo deseable es que exista un proceso de discusión y diálogo intercultural para definir las necesidades y anhelos de las poblaciones comprometidas en las políticas. El carácter participativo de las políticas interculturales alude al hecho de que no se pueden diseñar políticas sin preguntarle al otro sobre sus propias necesidades, deseos y sentires. No se puede hacer políticas para la otredad sin preguntarle al otro.

\section{Políticas de largo plazo o permanentes}

Quinto, las acciones afirmativas son de corto plazo y temporales, muchas veces tienen una función "analgésica" para canalizar el malestar que produce la inequidad social entre culturas ${ }^{103}$. Ello tiene que ver con su sesgo asimilacionista. Reconocen al otro discriminado como desigual y por ello se orientan a mejorar la igualdad de oportunidades para que pueda acceder a los espacios que le están vedados. Pero no lo reconoce como diferente, lo que requiere afirmar su diferencia al tiempo que se propende por alcanzar la equidad en las relaciones con miembros de otras culturas. Las acciones afirmativas propugnan por la igualdad entre culturas, pero no resaltan las diferencias. Su objetivo es hacer que los grupos culturales desfavorecidos se integren en igualdad de condiciones a la cultura mayoritaria, avanzando hacia una sociedad donde no es necesario el trato diferenciado a lo que es diferente, más que favorecer el desarrollo de la diversidad.

En contraste, las políticas interculturales suponen un reconocimiento de la diferencia en forma permanente. Por eso, deberían operar permanentemente. Una vez se mitigue inequidad entre grupos culturales, se requieren políticas que salvaguarden la diversidad cultural y preparen los distintos grupos para la interacción, para prevenir la opresión y la discriminación. Así se atenúa su sesgo integracionista. Según Tubino ${ }^{104}$, las políticas interculturales son de largo plazo. Buscan transformar las estructuras simbólicas donde se desenvuelven las relaciones entre diferentes.

En suma, las políticas interculturales se distinguen de las acciones afirmativas porque en vez de distinguir entre culturas 
mayoritarias y minoritarias, distinguen las dominantes de las subalternas; articulan la justicia cultural con la justicia social, no solo para atacar las consecuencias de la desigualdad entre culturas, la discriminación, sino sobre todo sus causas estructurales; no solo apuestan por la coexistencia entre culturas, sino también por el diálogo, el respeto y la convivencia; y son políticas participativas y de largo plazo. 


\section{CONCLUSIONES}

Este trabajo se propuso establecer las diferencias entre las acciones afirmativas y las políticas interculturales, sosteniendo que las primeras son necesarias pero no suficientes para alcanzar los ideales de la interculturalidad. Esta categoría plantea un enfoque alternativo al multiculturalismo formulado por Kymlicka, para conseguir la justicia entre grupos culturales.

El interculturalismo adopta postulados de la perspectiva de Kymlicka, como la necesidad de los derechos diferenciados y la protección de los derechos individuales, pero, a partir de una crítica constructiva, plantea un enfoque diferente. Trata de ir más allá de la justicia formal basada en el reconocimiento de derechos y resalta la necesidad de cambios estructurales que ataquen las causas de la desigualdad y edifiquen una justicia sustancial. De esa forma, no solo articula la justicia cultural a la justicia social, sino que intenta superar los horizontes normativos de la tolerancia y la coexistencia, para promover el diálogo, el respeto, la convivencia y el aprendizaje mutuo entre culturas.

Las acciones afirmativas son necesarias para alcanzar esos ideales, principalmente la igualdad entre los miembros de distintas culturas, pero no son suficientes. Se requiere un tránsito hacia las políticas interculturales, que ataquen las causas socioeconómicas de la desigualdad más allá de sus consecuencias; que no solo se preocupen por suprimir la discriminación y facilitar la integración de los grupos culturales a la cultura dominante, sino que permitan el desarrollo de sus diferencias; que, en términos normativos, vayan más allá de la tolerancia y la coexistencia para alcanzar el respeto y la convivencia entre culturas; que involucren las diferentes culturas en su diseño e implementación en procesos dialógicos y participativos, y que funcionen a largo plazo o de forma permanente. 


\section{BIBLIOGRAFÍA}

\section{Libros}

André-Noël Roth \& Maguemati Wabgou, Las políticas públicas de las diversidades. Identidades y emancipación, Universidad Nacional de Colombia, Bogotá (2009).

Catherine Walsh, El pluralismo jurídico: el desafío de la interculturalidad, Novamérica, No. 133, 36 (2012).

Interculturalidad, Estado, Sociedad. Luchas (de)coloniales de nuestra época, Universidad Andina Simón Bolívar-Abya Yala, Quito, 28 (2009).

Consuelo Yánez, Educación indígena en Ecuador, Instituto de Capacitación MunicipalEdiciones de la Universidad Politécnica Salesiana, Quito, 71 (1996).

Daniel Bonilla, La ciudadanía multicultural y la política del reconocimiento, Bogotá, Universidad de los Andes (1999).

Eduardo Puente, El Estado y la interculturalidad en el Ecuador, Universidad Andina Simón Bolívar - Abya Yala - Corporación Editora Nacional, Quito, 15 (2005).

Eduardo Restrepo \& Axel Rojas, Inflexión decolonial: fuentes, conceptos y cuestionamientos, Instituto Pensar Pontificia Universidad Javeriana - Universidad del Cauca, Popayán, 91-114 (2010).

Fidel Tubino, Del interculturalismo funcional al interculturalismo crítico, en Rostros y fronteras de la identidad, Universidad Católica de Temuco, 158 (2004).

, El interculturalismo frente a los desafíos del pluralismo jurídico, en Caminos para la inclusión en la educación superior, Fondo Editorial Fundación Equitas, Lima, 195-196 (2007). $2(2003)$.

La praxis de la interculturalidad en los estados nacionales latinoamericanos, 3 Cuadernos Interculturales, No. 5, 84 (2005).

, Las ambivalencias de las acciones afirmativas, en Educar en ciudadanía intercultural, Universidad de la Frontera - Pontificia Universidad Católica del Perú, Lima, 91 (2007).

Jorge Viaña, Luis Claros \& Marcelo Sarzuri, Presentación, en Interculturalidad crítica $y$ descolonización. Fundamentos para el debate, Instituto Internacional de Integración del Convenio Andrés Bello, La Paz, 7 (2009).

Jorge Viaña, Reconceptualizando la interculturalidad, en Construyendo interculturalidad crítica, Convenio Andrés Bello, La Paz, 11-12 (2010).

Josef Esterman, Colonialidad, descolonización e interculturalidad. Apuntes desde la filosofía intercultural, en Interculturalidad crítica y descolonización. Fundamentos para el debate, Instituto Internacional de Integración del Convenio Andrés Bello, La Paz, 52 (2009).

Juan Ansion, La interculturalidad y los desafios de una nueva forma de ciudadanía, 
en Educar en ciudadanía intercultural, Universidad de la Frontera - Pontificia Universidad Católica del Perú, Lima, 44-45 (2007).

Nancy Fraser, Iustitia interrupta, Universidad de los Andes, Bogotá, 18 (1997).

Tzvetan Todorov, La conquista de América. El problema del otro, Siglo XXI, México, 293 (2010).

Víctor Torres, La acción pública intercultural, Abya Yala, Quito (2010).

Will Kymlicka, Ciudadanía multicultural, Paidós, Buenos Aires (1996).

\section{Contribuciones en obras colectivas}

Angelo Papachini, Comunitarismo, liberalismo y derechos humanos, en: F. Cortés \& A. Monsalve, Eds., Liberalismo y comunitarismo. Derechos humanos y democracia, 231-261, Edicions Alfons El Magnánim, Valencia (1996).

Boaventura de Souza Santos, Las paradojas de nuestro tiempo y la plurinacionalidad, en: Alberto Acosta \& Esperanza Martínez, Comps., Plurinacionalidad: democracia en la diversidad, Abya Yala, Quito (2009).

Camilo Borrero, ¿Multiculturalismo o interculturalidad?, en: D. Carrillo \& N. Patarroyo, Eds., Derecho, interculturalidad y resistencia étnica, Universidad Nacional de Colombia, Bogotá (2009).

Catherine Walsh, Acción afirmativa en perspectiva afroreparativa, en: J. Sánchez, V. Avendaño \& D. Caicedo, Eds., Pueblos afrodescendientes y derechos humanos. Del reconocimiento a las acciones afirmativas, Ministerio de Justicia, Derechos Humanos y Cultos del Ecuador - Oficina del Alto Comisionado de las Naciones Unidas para los Derechos Humanos, Quito (2011).

Claudia Mosquera, Margarita Rodríguez \& Ruby León, Las acciones afirmativas como medio de inclusión social. Énfasis conceptuales, polémicas frecuentes y experiencias de implementación en algunos países, en: C. Mosquera \& R. León, Eds., Acciones afirmativas y ciudadanía diferenciada étnico-racial negra, afrocolombiana, palenquera y raizal, Universidad Nacional de Colombia, Bogotá (2009).

Farid Benavides, La democracia liberal y el reto intercultural, en: D. Carrillo \& N. Patarroyo, Eds., Derecho, interculturalidad y resistencia étnica, Universidad Nacional de Colombia, Bogotá (2009).

Fidel Tubino, Entre el multiculturalismo y la interculturalidad: más allá de la discriminación positiva, en: Norma Fuller, Ed., Interculturalidad y política: desafíos y posibilidades, RDCSP, Lima (2005).

Francisco Colom, Las identidades culturales y la dinámica del reconocimiento, en: F. Cortés \& A. Monsalve, Coords., Multiculturalismo. Los derechos de las minorías culturales, Universidad de Antioquia, Murcia (1999).

Galo Ramón, ¿Plurinacionalidad o interculturalidad en la Constitución?, en: Alberto Acosta \& Esperanza Martínez, Comps., Plurinacionalidad: democracia en la diversidad, Abya Yala, Quito (2009).

Mario Blaser, Bolivia: los desafíos interpretativos de la coincidencia de una doble crisis hegemónica, en: P. Stefanoni \& H. Do Alto, Eds., Reinventando la nación en Bolivia. 
Movimientos sociales, Estado y poscolonialidad, Clacso-Plural, La Paz (2007).

Olivia Cortez, Acciones afirmativas para afrodescendientes: ¿un reconocimiento de justicia o redistribución de recursos?, en: J. Sánchez, V. Avendaño \& D. Caicedo, Eds., Pueblos afrodescendientes y derechos humanos. Del reconocimiento a las acciones afirmativas, Ministerio de Justicia, Derechos Humanos y Cultos del Ecuador - Oficina del Alto Comisionado de las Naciones Unidas para los Derechos Humanos, Quito (2011).

Óscar Mejía \& Daniel Bonilla, El paradigma consensual-discursivo del derecho como instrumento conciliador de la tensión entre multiculturalismo comunitarista y liberalismo multicultural, en: Multiculturalismo y los derechos de las minorías culturales, Res-Pública - Universidad de Antioquia, Murcia, 83-117 (1999).

Pastor Murillo, Las medidas de acción afirmativa o medidas especiales: para reparar las injusticias históricas y la discriminación, en: J. Sánchez, V. Avendaño \& D. Caicedo, Eds., Pueblos afrodescendientes y derechos humanos. Del reconocimiento a las acciones afirmativas, Ministerio de Justicia, Derechos Humanos y Cultos del Ecuador - Oficina del Alto Comisionado de las Naciones Unidas para los Derechos Humanos, Quito (2011).

Rita Segato, Racismo, discriminación y acciones afirmativas: herramientas conceptuales, en: Educar en ciudadanía intercultural, Universidad de la Frontera - Pontificia Universidad Católica del Perú (2007).

Will Kymlicka, El Nuevo debate sobre los derechos de las minorías, en: Ferrán Requejo, Ed., Democracia y pluralismo nacional, Ariel, Barcelona, 25-48 (2002).

\section{Revistas}

Andrés Donoso, Rafael Contreras, Leonardo Cubillos \& Luis Aravena, Interculturalidad y politicas públicas en Educación, XXXII Estudios pedagógicos, No. 1 (2006).

Aníbal Quijano, Colonialidad del poder y clasificación social, XI Journal of World-Systems Research, No. 2, 342-386 (2000).

Axel Rojas \& Elizabeth Castillo, Multiculturalismo y politicas educativas en Colombia ¿interculturalizar la educación?, Revista Educación y Pedagogía, No. 48 (2007)

Catherine Walsh, Interculturalidad, plurinacionalidad y decolonialidad: las insurgencias político-epistémicas de refundar el Estado, Tabula rasa, No. 9 (2008).

Ferrán Requejo, Pluralismo, democracia y federalismo. Una revisión de la ciudadanía democrática en estados plurinacionales, Revista Internacional de Filosofía Politica, No 7 (1996).

Fidel Tubino, El nivel epistémico de los conflictos interculturales, 7 Revista electrónica construyendo nuestra interculturalidad, No. 6-7 (2011).

, No una sino muchas ciudadanías: una reflexión desde el Perú y América Latina, 6 Cuadernos Interculturales, No. 10 (2008).

José Jorge De Carvalho, Los estudios culturales en América Latina: interculturalidad, acciones afirmativas y encuentro de saberes, Tabula Rasa, No. 12 (2010).

Ricard Zapata-Barrero, Diversidad y política pública, Papeles, No. 104 (2008). 
